\title{
Penerapan Algoritma Elephant Herding Optimization (EHO) pada Masalah Hybrid Flowshop Scheduling (HFS)
}

\author{
Ahmad Kamsyakawuni ${ }^{1 *}$, Khurnia Palupi ${ }^{2 *}$, Agustina Pradjaningsih ${ }^{3 *}$ \\ * Matematika, Fakultas Matematika dan Ilmu Pengetahuan Alam, Universitas Jember \\ kamsyakawuni.fmipa@unej.ac.id ${ }^{1}$, khurniapalupi@gmail.com ${ }^{2}$, agustina.fmipa@unej.ac.id ${ }^{3}$
}

\section{Article Info \\ Article history: \\ Received 2020-01-04 \\ Revised 2020-02-03 \\ Accepted 2020-02-04}

Keyword:

Elephant Herding Optimization (EHO), Hybrid Flowshop Scheduling (HFS), Makespan.

\begin{abstract}
The industry is the driving force for the economy in Indonesia. One of the problems faced by industrial companies in the production process is determining the production schedule. The production schedule that is not according to the specified target can cause losses to the company. Scheduling is the allocation of resources to carry out a set of work at a specified time. The problem solved in this article is hybrid flowshop scheduling (HFS); companies in bread making will be using it. A solution to solve the HFS problem using elephant herding optimization (EHO) algorithm. For the company to complete the production process by minimizing makespan, effective scheduling is needed, taking into account the number of parallel machines. This article experimented with nine (9) jobs and seven (7) stages of the production process. The results of this article makespan 11.270 seconds using the MATLAB software. EHO algorithm program on HFS problem can minimize time for 36 minutes 39 seconds.
\end{abstract}

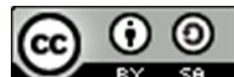

This is an open access article under the CC-BY-SA license.

\section{Pendahuluan}

Industri menjadi salah satu motor penggerak perekonomian di Indonesia [1]. Salah satu masalah yang dihadapi oleh perusahaan industri dalam proses produksi adalah menentukan jadwal produksi. Jadwal produksi yang tidak sesuai dengan target yang ditentukan dapat menyebabkan kerugian pada perusahaan. Penjadwalan dalam produksi penting dilakukan agar memaksimalkan produksi dan menghindarkan perusahaan dari proses produksi yang tidak sesuai target. Penjadwalan adalah kegiatan pengalokasian sumber daya atau mesin yang ada untuk menjalankan sekumpulan tugas dalam jangka waktu tertentu. Dalam proses produksi terdapat tiga elemen penjadwalan yaitu job, operasi dan mesin [2].

Hybrid flowshop scheduling (HFS) merupakan penjadwalan proses produksi paralel yang memiliki mesin identik dengan urutan proses produksi searah [3]. HFS terdiri atas $n$ job $(J\{1,2, \ldots, n\})$ diproses pada $k$-stage. Terdapat $m_{i}$ mesin yang identic pada stage $i$. Job $j$ harus diproses secara serentak pada size $_{i j}$ mesin paralel yang identik pada stage $i$ selama $t_{i j}$ satuan waktu. Tujuannya adalah mencari urutan penjadwalan yang meminimumkan makespan $\left(C_{\max }\right)$, dimana $t_{i j}$ adalah waktu proses job $j$ pada stage $i$ dan size $_{i j}$ banyaknya mesin yang dibutuhkan untuk memproses job $j$ pada stage $i[4]$.

Agar perusahaan dapat menyelesaikan proses produksi sesuai target dengan meminimumkan makespan, diperlukan solusi dengan penjadwalan yang efektif. Solusi permasalahan HFS dapat dicari dengan menggunakan metode metaheuristik. Metode metaheuristik bersifat general, tidak bergantung pada jenis permasalahan sehingga dapat diterapkan berbagai macam permasalahan [5]. Metode metaheuristik dapat memberikan kemungkinan solusi yang mendekati solusi optimal [6]. Salah satu algoritma yang dapat menyelesaikan masalah optimasi adalah algoritma elephant herding optimization (EHO) yang terinspirasi dari perilaku menggiring kelompok gajah. Algoritma EHO dibandingkan dengan algoritma lain, yaitu biogeography-based optimization (BBO), differential evolution (DE) dan genetic algorithm (GA) pada masalah optimasi fungsi. Berdasarkan hasil perbandingan solusi yang didapat dengan algoritma EHO mendekati optimal dibandingkan ketiga algoritma ini [7].

Pratiwi (2019) telah menyelesaikan HFS pada perusahaan spring bed dengan algoritma migrating birds optimization (MBO). Hasil penelitian didapat algoritma MBO efektif dalam menyelesaiakan HFS karena makespan yang dihasilkan lebih optimal dari makespan perusahaan [8] 
Regita (2019) telah berhasil meneliti masalah multiple constraints knapsack 0-1 yang diselesaikan dengan menggunakan algoritma EHO. Hasil penelitian didapat algortima EHO efektif mendapatkan keuntungan lebih optimal dari metode simpleks [9]. Berkaitan dengan hal tersebut, artikel ini menggunakan algoritma EHO pada permasalahan optimasi lain. Sehingga akan membahas lebih lanjut penerapan algoritma EHO pada masalah HFS. Artikel ini bertujuan mendapatkan solusi penjadwalan job dengan makespan minimum sekaligus pembuatan program menggunakan software MATLAB. Hasil makespan menggunakan algoritma EHO akan dibandingkan dengan makespan awal penjadwalan perusahaan. Manfaatnya memberikan alternatif penyelesaian penjadwalan dengan meminimasi makespan.

Evaluasi performasi algoritma diujikan pada benchmark problems. Belum adanya informasi mengenai solusi optimal pada benchmark problems atau pada data primer diakomodasi dengan penggunaan lower bound (LB), yaitu batas bawah (nilai minimum). Kriteria yang umum digunakan pada masalah HFS adalah makespan. Nilai Lower Bound dapat dihitung menggunakan persamaan (1)

$$
\begin{aligned}
& L B= \max _{i \in M}\left\{\min _{j \in J}\left\{\sum_{l=1}^{i-1} t_{l j}\right\}+\max \left\{\left(\left[\frac{1}{m_{i}} \sum_{j \in J} t_{i j} \cdot\right.\right.\right.\right. \\
&\left.\left.\operatorname{size}_{i j}\right]\right),\left(\sum_{j \in A_{i}} t_{i j}+\left[\frac{1}{m_{i}} \sum_{j \in B_{i}} t_{i j} .\right.\right. \\
&\left.\left.\left.\left.\operatorname{size}_{i j}\right]\right)\right\}+\min _{j \in J}\left\{\sum_{l=i+1}^{k} t_{l j}\right\}\right\}
\end{aligned}
$$

dimana,

$$
A_{i}=\left\{j \mid \text { size }_{i j}>\frac{m_{i}}{2}\right\}, \quad B_{i}=\left\{j \mid \operatorname{size}_{i j}=\frac{m_{i}}{2}\right\}[10]
$$

Perbandingan antara makespan dan lower bound dilakukan dengan menghitung persentase deviasi atau Percentage Deviation Algorithm (PDA). Perhitugan persentase deviasi adalah sebagai berikut

$\operatorname{PDA}(l)=100 \% \times \frac{C_{\max }(l)-L B}{L B}$

Tahap pemecahan masalah optimasi dengan menggunakan algoritma EHO sebagai berikut:

1) Clan Updating Operator

Posisi baru setiap gajah dalam kelompok $c_{i}$ dipengaruhi oleh posisi matriacrh $c_{i}$. Posisi gajah $j$ dalam masalah HFS sebagai urutan job diperbarui berdasarkan persamaan 3 . $x_{n e w, c_{i, j}}=x_{c_{i, j}}+\alpha\left(x_{\text {best }, c_{i}}-x_{c_{i, j}}\right) r$

dengan,

$x_{n e w, c_{i, j}} \quad$ : posisi baru untuk gajah $j$ di kelompok $c_{i}$

$x_{c_{i, j}} \quad$ : posisi lama untuk gajah $j$ di kelompok $c_{i}$

$\alpha \quad$ : faktor skala yang menentukan matriarch $c_{i}$

$x_{\text {best }, c_{i}} \quad$ : gajah terbaik di kelompok $c_{i}$ (matriarch $\left.c_{i}\right)$

$r \quad$ : bilangan random pada interval $[0,1]$

Matriarch sebagai urutan job yang menghasilkan makespan terkecil memperbarui posisinya dengan persamaan (2.4).

$$
x_{n e w, c_{i, j}}=\beta x_{\text {center }, c_{i}}
$$

dengan,

$\beta \quad$ : faktor yang menentukan pengaruh $x_{\text {center }, c_{i}}$

$x_{\text {center }, c_{i}}$ : pusat kelompok dihitung berdasarkan

persamaan (5)

$$
x_{\text {center }, c_{i}}=\frac{1}{n_{c_{i}}} \sum_{j=1}^{n_{c_{i}}} x_{c_{i, j}}
$$

dengan,

$x_{\text {center, } c_{i}}$ : pusat kelompok $c_{i}$

$n_{c_{i}} \quad$ : jumlah gajah dalam kelompok $c_{i}$

$x_{c_{i, j}} \quad$ : posisi gajah $j$ di kelompok $c_{i}$

\section{2) Separating Operator}

Gajah jantan akan meinggalkan kelompoknya dan hidup sendiri ketika dewasa. Proses memisahkan diri dapat dimodelkan dalam separating operator. Fitness adalah kemampuan yang dimiliki setiap gajah. Pada permasalahan ini makespan digunakan sebagai tolak ukur kemampuan yang dimiliki setiap gajah. Gajah dengan fitness terkecil dengan kata lain posisi gajah yang menghasilkan makespan terbesar menerapkan separating operator yang ditunjukan dalam persamaan (6).

$x_{\text {worst }, c i}=x_{\min }+\left(x_{\max }-x_{\min }+1\right)$ rand dengan,

$x_{\max } \quad$ : batas atas dari posisi individu gajah

$x_{\min } \quad:$ batas bawah dari posisi individu gajah

$x_{\text {worst,ci }} \quad:$ individu gajah terburuk kelompok

rand : bilangan random dalam interval $[0,1]$

[3]

\section{Metode Penelitian}

\section{A. Data Penelitian}

Data yang digunakan dalam artikel ini berupa data job, data waktu proses produksi, data mesin dan tahapan produksi pada perusahaan yang bergerak dibidang pembuatan roti. Artikel ini melakukan percobaan menggunakan 9 job dan 7 tahap proses produksi (stage). Uji parameter dengan nilai yang digunakan $n$ Clan dan $n c_{i}$ adalah $10,15,20 . \mathrm{Uji}$ parameter dengan nilai yang digunakan $\alpha$ dan $\beta$ adalah 0,01 ; 0,$5 ; 0,9$. Setiap kombinasi parameter menggunakan 10 kali percobaan dengan maksimum iterasi 500.

\section{B. Skema Langkah Penelitian}

Langkah-langkah yang dilakukan adalah

1) Mengumpulkan dan mempelajari literatur yang berkaitan dengan algoritma EHO dan masalah HFS

2) Pengambilan Data: Data yang digunakan berupa data job, data waktu proses produksi, data mesin, dan tahapan produksi. Data yang digunakan sembilan job tujuh stage.

3) Penerapan algoritma EHO

4) Pengecekan kriteria pemberhentian dan memilih solusi: Jika iterasi telah mencapai iterasi maksimal, maka proses dihentikan dan solusi terbaik didapat. 
5) Pembuatan Program: Pembuatan program penerapan algoritma EHO pada masalah HFS dilakukan menggunakan software MATLAB.

6) Simulasi Program: Melakukan simulasi pada program yang telah dibuat.

7) Analisis Hasil: Hasil penjadwalan akan dibandingkan dengan lower bound, untuk mengetahui nilai PDA menggunakan persamaan (2). Semakin kecil nilai PDA maka semakin optimal atau lebih efektif penjadwalan pada algoritma tersebut. Hasil penjadwalan program nantinya akan dibandingkan dengan hasil makespan awal penjadwalan perusahaan.

8) Kesimpulan: Membuat kesimpulan dari hasil yang telah diperoleh.

Gambar 1 merupakan skema langkah penelitian.

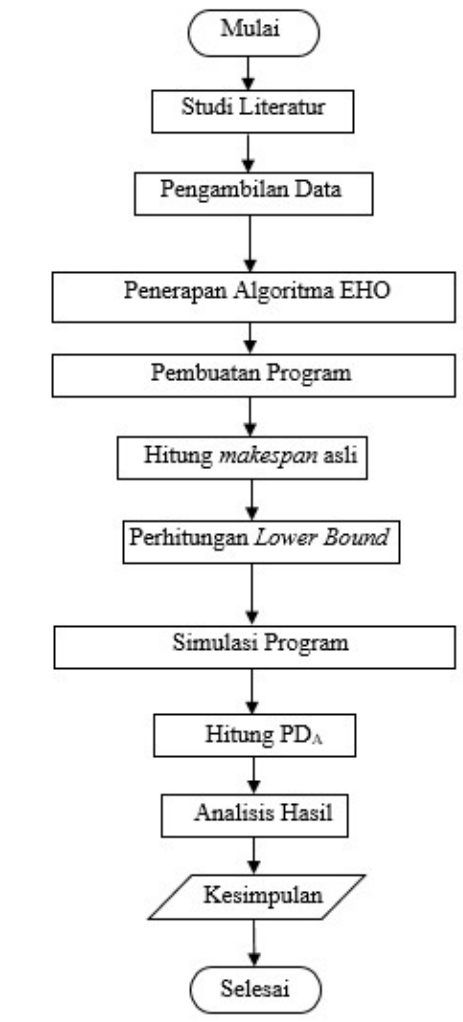

Gambar 1. Skema langkah penelitian

\section{Penerapan Algoritma EHO pada Masalah HFS}

Langkah - langkah penerapan algoritma EHO pada masalah HFS dengan data yang telah diidentifikasi adalah sebagai berikut:

1) Inisialisasi populasi awal: Inisialisasi populasi awal dilakukan dengan cara membangkitkan secara acak $(X)$ pada selang $[-4,4]$, tahap selanjutnya $(X)$ diurutkan dari nilai terkecil didapat $(Y)$ sebagai posisi awal berupa urutan job dan menghitung total waktu produksi (makespan) masing-masing job.
2) Menyimpan Matriarch: Menentukan matriarch yaitu solusi awal dengan nilai makespan terkecil dalam setiap kelompok.

3) Clan Updating Operator: Pada solusi awal akan dilakukan clan updating operator dengan setiap posisi $(X)$ diperbarui menggunakan persamaan (3) dan posisi matriarch menggunakan persamaan (4). Solusi baru tersebut akan dihitung nilai makespan.

4) Separating Operator: Posisi ( $X)$ dengan makespan terbesar dalam setiap kelompok akan menerapkan separating operator menggunakan persamaan (6). Didapat posisi baru dan menghitung nilai makespan.

5) Updating Matriach: Jika matriarch baru memiliki makespan lebih kecil dari matriarch lama maka akan menggantikan matriarch lama. Jika tidak, maka matriarch lama dipertahankan.

\section{Hasil dan PeMbahasan}

Perhitungan HFS dilakukan dengan bantuan software MATLAB. Setelah dilakukan pengujian parameter (Tabel I), dapat diketahui beberapa parameter yang perlu diperhatikan untuk mencari solusi optimal. Simulasi akhir dengan nilai parameter yang digunakan $\mathrm{nClan}=125 ; \mathrm{nCi}=15 ; \alpha=0,9 ; \beta$ $=0,9$ dengan menggunakan dua iterasi maksimal yaitu, 500 dan 1000. Hasil dari simulasi program dapat dilihat pada Tabel II dan Tabel III.

TABEL I

UJI PARAMETER 9 JOB DAN \& STAGE ITERASI MAKSIMUM 500

\begin{tabular}{|c|c|c|c|c|c|c|c|}
\hline \multirow[b]{2}{*}{ No. } & \multicolumn{4}{|c|}{ Nilai Parameter } & \multirow{2}{*}{$\begin{array}{l}\text { Rata-rata } \\
\text { Makespan }\end{array}$} & \multirow{2}{*}{$\begin{array}{l}\text { Rata- } \\
\text { rata } \\
\text { Iterasi }\end{array}$} & \multirow{2}{*}{$\begin{array}{c}\text { Rata-rata } \\
\text { Waktu } \\
\text { Komputasi }\end{array}$} \\
\hline & nClan & $n c_{i}$ & $\alpha$ & $\beta$ & & & \\
\hline 1 & 10 & 10 & 0,5 & 0,5 & $11.350,7$ & 145,8 & 147,91105 \\
\hline 2 & 15 & 10 & 0,5 & 0,5 & $11.334,4$ & 156,3 & 189,21 \\
\hline 3 & 20 & 10 & 0,5 & 0,5 & $11.321,3$ & 152,8 & 266,92539 \\
\hline 4 & 20 & 15 & 0,5 & 0,5 & 11.279 & 163,5 & 335,4813 \\
\hline 5 & 20 & 20 & 0,5 & 0,5 & $11.274,7$ & 253,9 & 485,70427 \\
\hline 6 & 15 & 15 & 0,01 & 0,01 & 11.417 & 260,5 & 316,67408 \\
\hline 7 & 15 & 15 & 0,5 & 0,5 & 11.315 & 193,7 & 288,72076 \\
\hline 8 & 15 & 15 & 0,01 & 0,9 & $11.329,7$ & 248,1 & 299,3128 \\
\hline 9 & 15 & 15 & 0,5 & 0,9 & $11.325,7$ & 211 & 263,1874 \\
\hline 10 & 15 & 15 & 0,9 & 0,9 & 11.330 & 165 & 293,6641 \\
\hline
\end{tabular}

TABEL II

SIMULASI AKHIR ITERASI MAKSIMUM 500

\begin{tabular}{cccccc}
\hline No. & Makespan & $\begin{array}{c}\text { Waktu } \\
\text { komputasi }\end{array}$ & PDA & Iter & $\begin{array}{c}\text { Urutan } \\
\text { job }\end{array}$ \\
\hline 1 & 11270 & 2229,7492 & 35,1319 & 32 & $\begin{array}{c}8-4-1-2- \\
6-3-9-5-7\end{array}$ \\
\hline 2 & 11270 & 2165,4557 & 35,1319 & 39 & $\begin{array}{c}8-4-1-2- \\
6-3-9-5-7\end{array}$ \\
\hline 3 & 11270 & 2160,6316 & 35,1319 & 16 & $\begin{array}{c}8-4-1-2- \\
6-3-9-5-7\end{array}$ \\
\hline 4 & 11270 & 2560,8959 & 35,1319 & 19 & $\begin{array}{c}8-4-1-2- \\
6-3-9-5-7\end{array}$ \\
\hline 5. & 11270 & 3367,9719 & 35,1319 & 3 & $\begin{array}{c}8-4-1-2- \\
6-3-9-5-7\end{array}$ \\
\hline 6 & 11270 & 2954,2226 & 35,1319 & 28 & $\begin{array}{c}8-4-1-2- \\
6-3-9-5-7\end{array}$ \\
\hline
\end{tabular}




\begin{tabular}{cccccc}
\hline 7 & 11270 & 2262,8068 & 35,1319 & 23 & $\begin{array}{c}8-4-1-2- \\
6-3-9-5-7\end{array}$ \\
\hline 8 & 11270 & 2168,0995 & 35,1319 & 37 & $\begin{array}{c}8-4-1-2- \\
6-3-9-5-7\end{array}$ \\
\hline 9 & 11270 & 2168,5286 & 35,1319 & 7 & $\begin{array}{c}8-4-1-2- \\
6-3-9-5-7\end{array}$ \\
\hline 10 & 11270 & 2176,3957 & 35,1319 & 335 & $\begin{array}{c}8-4-1-2- \\
6-3-9-5-7\end{array}$ \\
\hline \multicolumn{2}{c}{ Rata-rata } & 2421,476 & 35,1319 & 54 & \\
\hline
\end{tabular}

TABEL III

SIMULASI AKHIR ITERASI MAKSIMUM 1000

\begin{tabular}{cccccc}
\hline No. & Makespan & $\begin{array}{c}\text { Waktu } \\
\text { komputasi }\end{array}$ & PDA & Iter & $\begin{array}{c}\text { Urutan } \\
\text { job }\end{array}$ \\
\hline 1 & 11270 & 4594,7852 & 35,1319 & 379 & $\begin{array}{c}8-4-1-2- \\
6-3-9-5-7\end{array}$ \\
\hline 2 & 11270 & 4593,4616 & 36,1319 & 540 & $\begin{array}{c}8-4-1-2- \\
6-3-9-5-7\end{array}$ \\
\hline 3 & 11270 & 4559,72 & 35,1319 & 35 & $\begin{array}{c}8-4-1-2- \\
6-3-9-5-7\end{array}$ \\
\hline 4 & 11270 & 4589,0976 & 35,1319 & 321 & $\begin{array}{c}8-4-1-2- \\
6-3-9-5-7\end{array}$ \\
\hline 5. & 11270 & 4398,6221 & 35,1319 & 77 & $\begin{array}{c}8-4-1-2- \\
6-3-9-5-7\end{array}$ \\
\hline 6 & 11270 & 4603,6599 & 35,1319 & 246 & $\begin{array}{c}8-4-1-2- \\
6-3-9-5-7\end{array}$ \\
\hline 7 & 11270 & 4583,9461 & 35,1319 & 95 & $\begin{array}{c}8-4-1-2- \\
6-3-9-5-7\end{array}$ \\
\hline 8 & 11270 & 4495,5496 & 35,1319 & 285 & $\begin{array}{c}8-4-1-2- \\
6-3-9-5-7\end{array}$ \\
\hline 9 & 11270 & 4723,8971 & 35,1319 & 64 & $\begin{array}{c}8-4-1-2- \\
6-3-9-5-7\end{array}$ \\
\hline 10 & 11270 & 4625,2816 & 35,1319 & 9 & $\begin{array}{c}8-4-1-2- \\
6-3-9-5-7\end{array}$ \\
\hline & Rata-rata & 4576,802 & 35,1319 & 206 & 6 \\
\hline
\end{tabular}

Berdasarkan uji parameter dapat dilihat pada Tabel I, hasil yang diperoleh bahwa parameter mempengaruhi pencapaian solusi optimal. Parameter $n C l a n$ dan $n c_{i}$ semakin besar maka solusi yang dibangkitkan semakin banyak sehingga kandidat solusi baru yang muncul lebih banyak. Dengan demikian kemungkinan didapatkan solusi optimal lebih tinggi. Semakin besar nilai parameter $\alpha$ dan $\beta$ yang diberikan tidak menjamin dapat lebih baik dalam pencarian solusi. Hal ini karena hasil perhitungan parameter $\alpha$ dan $\beta$ menentukan urutanan job yang mempengaruhi makespan. Iterasi maksimal tidak begitu mempengaruhi hasil yang didapat jika populasi yang dibangkikan cukup besar, semakin banyak iterasi maka waktu penyelesaian program semakin lama. Hasil penelitian parameter mempengaruhi makespan yang dihasilkan dari urutan job. Jumlah populasi yang dibangkitkan sangat mempengaruhi hasil yang didapat. Setelah dilakukan uji simulasi akhir pada program hasil makespan terbaik dapat dilihat pada Tabel II dan Tabel III. Penjadwalan HFS dengan 9 job 7 stage menghasilkan solusi optimal yaitu 11.270 detik dengan rata-rata konvergen terbaik 54; rata-rata waktu komputasi terbaik 2421,476 detik; dan PDA sebesar 35,1319\%. Waktu optimal perusahaan memproduksi roti selama 3 jam 7 menit 50 detik dengan urutan job 8-4-1-2-6-3-9-5-7. Makespan sesuai urutan awal perusahaan yaitu 13.469 detik artinya perusahaan produksi roti selama 3 jam 44 menit 29 detik dengan urutan job 1-2-34-5-6-7-8-9 dan PDA 61,4988\%. Pengerjaan masalah HFS dengan menggunakan program algoritma EHO dapat meminimalisir waktu selama 36 menit 39 detik. Sehingga algortima EHO efektif menyelesaikan masalah HFS karena makespan yang dihasilkan program lebih optimal dari makespan awal perusahaan.

\section{KESIMPULAN}

Berdasarkan hasil dan pembahasan dapat ditarik kesimpulan EHO efektif dalam menyelesaikan masalah HFS karena hasil yang diperoleh mendekati nilai optimal dilihat berdasarkan hasil 10 kali percobaan dengan nilai PDA 35,1319\% dan menghasilkan makespan yaitu 11.270 detik. Parameter yaitu, kelompok gajah $($ nClan $)=125$, jumlah gajah dalam kelompok $\left(n c_{i}\right)=15 ; \alpha=0,9 ; \beta=0,9$; dan maksimum iterasi menggunakan dua iterasi maksimal yaitu, 500 dan 1000.

\section{DAFTAR PUSTAKA}

[1] Latief, M. N. 2018. Indonesia Bangun Manufaktur sebagai Penggerak Perekonomian. Anadolu Agency.

https://www.aa.com.tr/id/ekonomi/indonesia-bangun-manufaktursebagai-penggerak-perekonomian/1048439 [Diakses pada 2 Mei 2019].

[2] Ginting, R. 2009. Penjadwalan Mesin. Yogyakarta: Graha Ilmu.

[3] Engin Orhan dan Engin Batuhan. 2017. Hybrid flowshop with multiprocessor task scheduling based on earliness and tardiness penalties. Journal of Enterprise Information Management

[4] Ogus, C. dan M. F. Ercan. 2005. A Genetic Algorithm for Hybird Flowshop Scheduling with Multiprocessor Tasks. Journal of Scheduling. 8(4): 323-351.

[5] Blum, C. dan A. Roli. 2003. Metaheuristics in Combinatoria Optimization. ACM Computing Surveys. 35(3): 268-308.

[6] Hillier, F. S. dan G. J. Lieberman. 2010. Introduction to Operations Research: Ninth edition. Standford University.

[7] Wang, G., S. Deb, dan L. S. Coelho. 2015. Elephant herding Optimization. Conference Paper: 2015 3rd International Symposium on Computational and Business Intelligence. IEEE

[8] Pratiwi, Y. E. 2019. Penyelesaian Masalah Hybird Flowshop Scheduling (HFS) dengan Algoritma Migrating Birds Optimization (MBO). Skripsi. Jember: Jurusan Matematika FMIPA Universitas Jember.

[9] Regita, Y. D. 2019. Penerapan Algoritma Elephant Herding Optimization (EHO) pada Permasalahan Multiple Constraints Knapsack 0-1. Skripsi. Jember: Jurusan Matematika FMIPA Universitas Jember.

[10] Komaki, G. M, Teymourian Ehsan dan Kayvanfar Vafid. 2015. Minimising makespan in the two-stage assembly hybrid flowshop scheduling problem using artificial immune systems. International Journal of Production Research 